\title{
Behavioral Control of Swash-Riding in the Clam Donax variabilis
}

\author{
OLAF ELLERS* \\ Department of Zoology, Duke University, Durham, North Carolina 27706
}

\begin{abstract}
Clams of the species Donax variabilis migrate shoreward during rising tides and seaward during falling tides. These clams spend most of the time in the sand, emerging several times per tidal cycle to ride waves. Migration is not merely a passive result of waves eroding clams out of the sand; rather clams actively jump out of the sand and ride specific waves. Such active migration is experimentally demonstrated during a falling tide by comparing the motion of dead and live clams; live clams emerge from the sand and move seaward even when dead ones do not. As low tide approaches, live clams become progressively less active. They cease migrating for 2 hours around low tide and resume jumping to migrate shoreward after the tide has turned. During the rising tide, far from being passive, the clams jump out to ride only the largest $20 \%$ of waves. Specifically, they choose swash that have the largest excursion, i.e., those swash that move furthest on the beach.
\end{abstract}

\section{Introduction}

The coquina clam, Donax variabilis, lives on southeastern North American shores on coarse-grained, sandy beaches with moderate to high waves. $D$. variabilis migrates shoreward with the rising tide and seaward with the falling tide, as do many other animals that live on wave-exposed beaches (e.g., other Donax spp., mole crabs, mysids, gastropods, amphipods, and isopods: McLachlan et al., 1979).

Migration by $D$. variabilis is accomplished in a series of steps. Most of the time, these clams stay in the sand. Several times per tidal cycle, each clam emerges from the sand and flow from waves drags it to a new position where

Received 9 September 1994; accepted 27 July 1995.

* Current address: Section of Evolution and Ecology, Division of Biological Sciences, University of California, Davis, CA 95616. it again digs in. I have named this method of locomotion "swash-riding" (Ellers, 1987, 1988), where swash-riding is the process of emerging from the sand, riding flow from a wave, and digging in again. Swash-riding does not necessarily lead to migration. For instance, $D$. faba swashrides without migrating (McLachlan and Hesp, 1984), and a gastropod, Bullia digitalis, swash-rides and uses positive chemotaxis to locate moving prey in the surf and swash zones (Odendaal et al., 1992). But in D. variabilis, a series of swash-rides usually becomes a migration. By migrating, a clam maintains its position at the sea's edge, i.e., in the region of the beach that is alternately underwater and exposed to air every few seconds as waves arrive on the shore.

In the tumultuous milieu of breaking waves, eroding sand, and rip currents at the edge of such a beach, how much control do these clams have over their migrations? One reasonable hypothesis is that the clams are eroded forcibly out of the sand by waves during a falling tide and that they then must swash-ride shoreward during the incoming tide to maintain their intertidal location on the beach.

That hypothesis has some support. Jacobson (1955) suggested that $D$. fossor was migrating as the passive result of wave action. Wade (1967a) suggested that emergence of $D$. denticulatus into the backwash was usually a passive result of clams being washed out of the sand. Mikkelsen (1981) described two populations of $D$. variabilis: one population lived on a high-slope beach with relatively large waves and migrated; the other population lived on a lowslope beach with smaller waves and did not migrate. Beaches with lower slopes and smaller waves have been associated with non-migratory or partially migratory populations (e.g., in D. striatus: Wade, 1967b; in D. gouldii: Irwin, 1973). Edgren (1959) described a population of $D$. variabilis that migrated only after a storm. Those 
observations suggest that migration might be a passive, wave-driven process.

An alternative hypothesis is that the clams choose to migrate, behaviorally maintaining their position at the sea's edge. In this alternative view, clams are not usually washed out of the sand; rather they actively push themselves out using their feet. In this view, physical disturbance is neither the proximal nor the ultimate cause of migration. Instead, other ultimate causes arc imaginablc. Perhaps more filterable food is available in water stirred up by waves, and the clams are merely following the food. Many aspects of migration could be beneficial: avoiding predators, or avoiding the overheating that might occur if they remained behind in the intertidal during the falling tide. No specific ultimate cause for migration is advocated in the present paper; the main point is to distinguish between clams being forcibly dislodged by waves and clams actively emerging to ride waves.

In marine invertebrates there are many other migratory behaviors in which the relative contributions of active and passive determinants of net motion are important. For instance, the diurnal vertical migrations of brachyuran larvae may determine the direction of transport by currents: early larval stages spend nights in the neuston when land breezes tend to transport them offshore; later larval stages migrate down during the night hours, and surface currents from sea breezes thus tend to transport them onshore (Shanks, 1986). The net movement of hypothetical invertebrate larvae has been modeled in computer simulations that evaluated the relative influence and interaction of light- and tide-cued vertical migrations, swimming speed, turbulent mixing, and tidal and nontidal flows (Smith and Stoner, 1993); in specific tidal channels modeled, nontidal flows dominated the effect of vertical migration. For lobster larvae, a combination of directed swimming of fourth stage larvae and ocean currents was necessary to account for onshore recruitment (Katz et al., 1994). Interactions of behavior and passive movement by flow are thus important to the biology of marine invertebrate larvae.

Passive movement by flows is not only important in the larval phase, but can also be significant in the juvenile or adult phases. The adults of a botryllid ascidian dispersed 200 times further by rafting in currents than did swimming larvae of the same species (Worcester, 1994). Further, adults of 17 mollusc species (with or without a planktonic larval phase) and an asteroid have been observed dispersing by rafting (Martel and Chia, 1991). In a tellinid bivalve, Macoma balthica, postlarval juveniles migrated to new tidal flat habitats by secreting long hyaline threads and being dragged by currents (Beukema and de Vlas, 1989), or by becoming positively buoyant and floating in currents (Sörlin, 1988). The latter is an inducible response to a combined stimulus of temperature change and water movement. In all these examples, animals achieve movement to new locations by a combination of behavioral and passive phenomena. In this and following papers (Ellers, 1995a, b) I investigate the relative contributions of passive and active factors to migratory movements of another tellinacean clam.

That $D$. variabilis clams choose to migrate in the shoreward direction is easily observed because, during rising tides, clams emerge from sand before an incoming wave reaches the location where they are buried. However, during the falling tide, clams emerge directly into the backwash; the question of whether this emergence is active or passive thus cannot be answered by direct observation, but can be addressed in a field experiment.

During the rising tide, when clams clearly choose to migrate, they might choose specific waves to ride, or they might merely jump in advance of random shorewardly moving waves. I present three field experiments: the first assesses whether clams actively jump out into the backwash during falling tides or are passively eroded by receding waves; the second observes clam behavior at low tide; the third demonstrates the degree to which these clams choose waves during the rising tide.

\section{Materials and Methods}

\section{Location}

All observations were made on sandy beaches near Pine Knoll Shores and Atlantic Beach, North Carolina. These beaches are on the outer coast of a barrier island, experience moderate to large waves, and have relatively coarsegrained sand. $D$. variabilis is densely but patchily distributed along the length of this island.

\section{Behavior during the falling tide}

To determine whether clams are eroded from the sand or actively push themselves out, paired dead and live clams were planted in the sand during a falling tide. Two hundred and thirty-four clams, killed by exposure to $30 \%$ alcohol, were marked with pink nail polish and planted in the beach, each one about 2 to $3 \mathrm{~cm}$ away from a live clam marked with red nail polish and similarly planted.

Locations of all the pink- and red-marked clams were designated with thin poles inserted into the beach. Poles were inserted sufficiently far from the planted clams that wave-caused erosion of sand around the poles did not excavate any experimental clams.

These clams were plantcd in four groups during a falling tide-4.0, 3.5, 2.5, and $1.5 \mathrm{~h}$ before low tide. They were planted in the wetted portion of the beach, i.e., in the swash zone, amidst other, actively migrating, $D$. variabilis. At low tide, when the poles were high and dry, the sand adjacent to the poles was dug up and clams of each color 


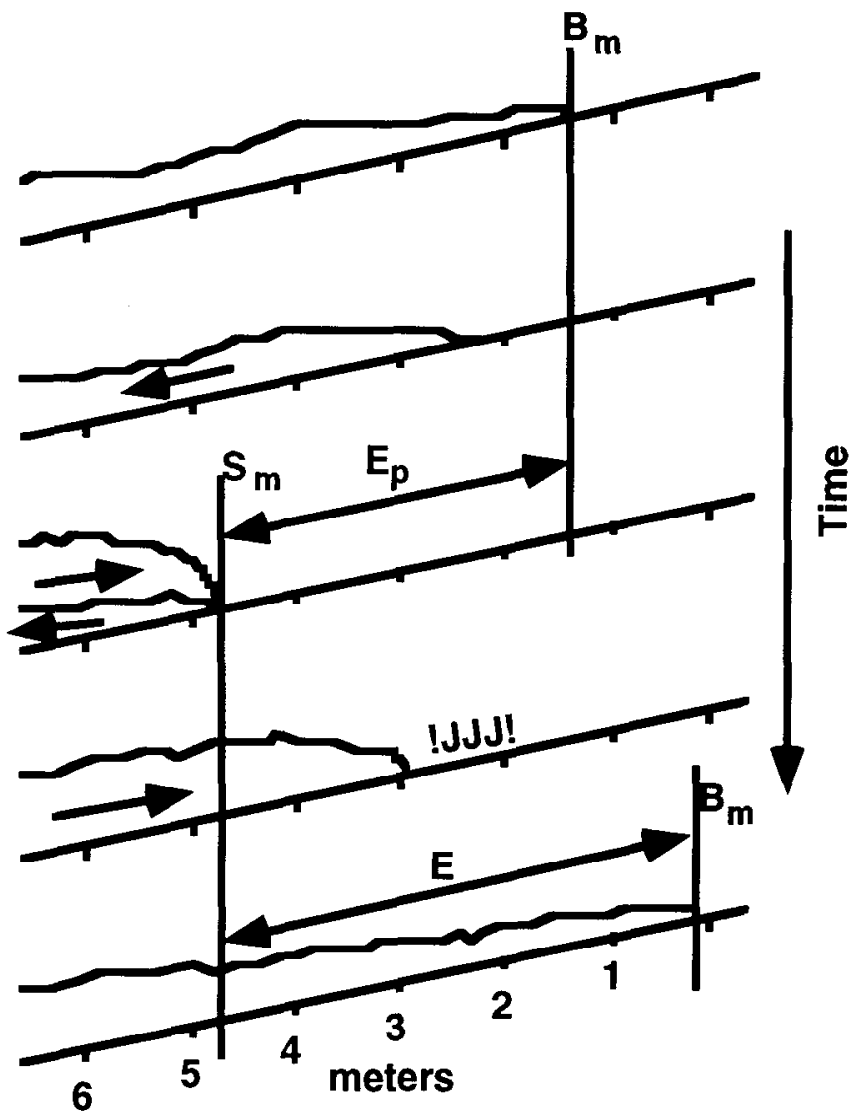

Figure 1. A smaller and then a larger wave on a beach, viewed in vertical section. Water directions are indicated with unidirectional arrows. !JJJ! indicates the place and time that clams might jump. The variables are (1) $\mathbf{B}_{m}$, the "beachward maximum," the position on the beach where the swash becomes backwash; (2) $\mathbf{S}_{\mathbf{m}}$, the "seaward minimum," the position on the beach where the previous backwash meets the swash; (3) E, the "excursion of the swash." the distance that the swash moves in the shoreward direction after passing the previous backwash; and (4) $E_{p}$, the "excursion of the previous backwash," the distance that the previous backwash moved in the seaward direction before passing the swash.

were counted. At the time they were planted, each group of clams had been divided topographically into subgroups of 4,5 , or 10 pairs of clams to facilitate subsequent statistical analysis ( 35 subgroups were created).

To test whether the erosion rates of dead clams in the above experiment were specific to the day on which that experiment was done, an additional 450 dead clams were planted during 6 different days over 3 summer months and the proportion remaining in their original locations was surveyed at low tide. This replication was done only with the dead clams because seaward movement of live clams during falling tides had been observed on hundreds of summer days during 3 years and was also documented in observations described in the next section.

One question that arises is whether marking live clams with nail polish itself influences the bchavior of clams.
Live clams handled and painted with nail polish, however, appeared to behave quite naturally after marking. A laboratory comparison of painted and unpainted clams showed similar burrowing speeds, similar emergence responses to knocking sound stimuli (see Ellers, 1995a, for an explanation of the stimulus), and similar siphon retraction responses to sudden light increases. Furthermore, field observations showed that marked clams released on the sand surface on the beach swash-rode and burrowed in a manner indistinguishable from naturally swash-riding clams. Finally, live marked clams were observed swashriding on the beach up to 2 months after marking. Thus, the marking procedure itself did not appear to adversely affect the behavior of clams.

\section{Behavior at low tide}

On 6 summer days during 1985, transects were dug at low tide, perpendicular to the long axis of the beach. The number of clams found in a $30-\mathrm{cm}$ by $30-\mathrm{cm}$ area was recorded every meter along the transect. The average position of the water's edge at low tide was also recorded. Behavior of clams was observed during the period from $1.5 \mathrm{~h}$ before to $1.5 \mathrm{~h}$ after low tide.

\section{Behavior during the rising tide}

Flags, painted with numbers 1 through 35 , were planted in a row perpendicular to the beach, in numerical sequence at $1-\mathrm{m}$ intervals. Flags bracketed the area of the beach wetted by swash and backwash-the base of the most shoreward flag was always dry; the most seaward flag was always wet.

The sea's edge moves seaward and shoreward alternately as waves reach the shore, wash up on the beach, and run off the beach again. The location of the edge of the water was monitored by recording each beachwardmaximum, $\mathbf{B}_{\mathbf{m}}$, and seaward-minumum, $\mathbf{S}_{\mathbf{m}}$, position (Fig. 1). Simultaneously, the activity of the clams was monitored. If clams jump, they do so after the water's edge has reached a seaward-minimum position and before the edge of the water reaches a new beachward-maximum position. Their behavior can thus be associated with a particular incoming swash.

Whether clams jumped for a particular swash was recorded during rising tides on 4 days in June and July. The excursion of the swash, $\mathbf{E}$, and the excursion of the previous backwash, $\mathbf{E}_{\mathbf{p}}$, were calculated by the appropriate subtractions of the relevant values of $\mathbf{B}_{m}$ and $\mathbf{S}_{\mathbf{m}}$ (Fig. 1). Observations were started not less than $1 \mathrm{~h}$ after low tide and were halted no more than $2 \frac{1}{2} \mathbf{h}$ before high tide. Observations on any particular day were made continuously for 1 to $2 \mathrm{~h}$ (Table I). 
Table I

Numbers of observations, frequency of swashes, and frequency of jumping on each of the 4 days of observations

\begin{tabular}{lcccc}
\hline \hline $\begin{array}{c}\text { \# of } \\
\text { Swashes }\end{array}$ & $\begin{array}{c}\text { \# of } \\
\text { Jumps }\end{array}$ & $\begin{array}{c}\text { Swashes/ } \\
\text { Min. }\end{array}$ & $\begin{array}{c}\text { Jumps/ } \\
\text { Swash }\end{array}$ \\
\hline 1 & 294 & 69 & 4.2 & 0.24 \\
2 & 379 & 85 & 4.9 & 0.22 \\
3 & 602 & 74 & 5.2 & 0.12 \\
4 & 481 & 149 & 5.3 & 0.31 \\
\hline
\end{tabular}

\section{Results}

\section{Behavior during the falling tide}

In trials involving live and dead clams, $50 \%-80 \%$ of dead clams were not eroded from the sand by waves (Fig. 2 ). In experiments involving only dead clams, an average of $49 \%$ (range of $43 \% 100 \%$ ) of the dead clams planted were not eroded from the sand; thus the trials with dead and live clams had typical erosion rates.

When dead and live clams were planted in pairs, a significantly larger proportion of live than dead clams left the sand in each of the four groups (Fig. 2). Only a tiny fraction, $4.7 \%$, of live clams that were planted 4 and $3 \mathrm{~h}$ before low tide stayed in the sand in their original positions and were recovered at low tide. Significantly more, $30 \%$ to $50 \%$, of live clams planted at $2 \mathrm{~h}$ before low tide stayed in the sand in their original positions and were recovered at low tide. Thus, as low tide approaches, more live clams stay in the sand. In contrast, dead clams planted close to the time of low tide washed out only slightly less often than clams planted closer to the time of high tide ( $P$ $=0.05$, Mann-Whitney $U$-test).

\section{Behavior at low tide}

At low tide, the population was found at or just shoreward of the average position of the water's edge (Fig. 3). A large fraction of the population was often found in sand that was no longer being wetted by even the most shorewardly reaching swash. The location of the center of the population varied relative to the average position of the waves at low tide. On 14 May, for instance, most of the population was at the average position of the water's edge at low tide. In contrast, on 5 June, the population was $22 \mathrm{~m}$ shoreward of the water's edge.

Many clams had stopped migrating and were essentially stranded during the $1-2 \mathrm{~h}$ around the time when the tide turns. From $0.5 \mathrm{~h}$ before low tide until $0.5 \mathrm{~h}$ after low tide, no clams were seen jumping oul of the sand. During the time from 0.5 to $1.5 \mathrm{~h}$ on either side of low tide, the numbers of clams seen jumping werc rclativcly low compared to the numbers of clams seen jumping during the middle of the rising tides. Although quantitative results are given for just 6 days, I observed the same pattern of cessation of migration around low tide during the three summers, May through August, I watched clam behavior on North Carolina beaches.

\section{Behavior during the rising tide}

D. variabilis clams evidently chose specific waves. Swash arrived on shore at an average rate of 5.0 swashes per minute during 1755 observed swashes. Clams jumped for $20 \%$ of these waves (Table I). On all 4 days, clams jumped for swash with relatively large excursion, E (Fig. 4A). Specifically, the clams jumped for a larger fraction of large than of small waves. The ratio $C / T$ (where $C$ is the number of swash chosen in a swash size-class and $T$ is the total number of swash in that size class) is the proportion of the swash of a given size that the clams ride. $C / T$ increases for increasing $\mathbf{E}$ on all 4 days.

The largest excursions of the swash are $\mathbf{E}=14$ to $18 \mathrm{~m}$; the smallest are $E=1$ to $4 \mathrm{~m}$. Choosing waves could make a large difference in the net motion of clams. Clams can move much further shoreward for each swash-ride by jumping into the largest swash instead of the smallest swash. For comparison, the intertidal width that clams traverse is 40 to $50 \mathrm{~m}$.

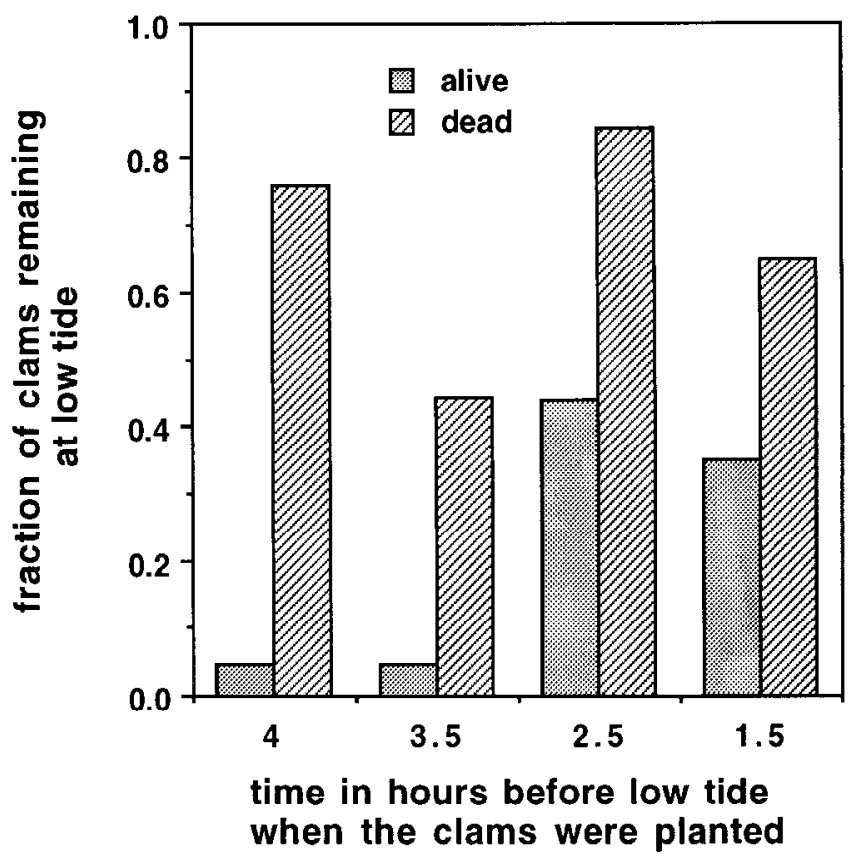

Figure 2. Fraction of dead and live $D$. variabilis remaining in the sand after being planted a certain number of hours before low tide. More live than dead clams leave the sand $(P<0.01$ ), suggesting that live clams choose to jump out. Fewer live clams leave the sand close to the time of low tide than leave at mid-tide $(P<0.01)$, suggesting that clams reduce or halt migration just before the time of low tide. (Probabilities were calculated using Mann-Whitney $U$-tests.) 

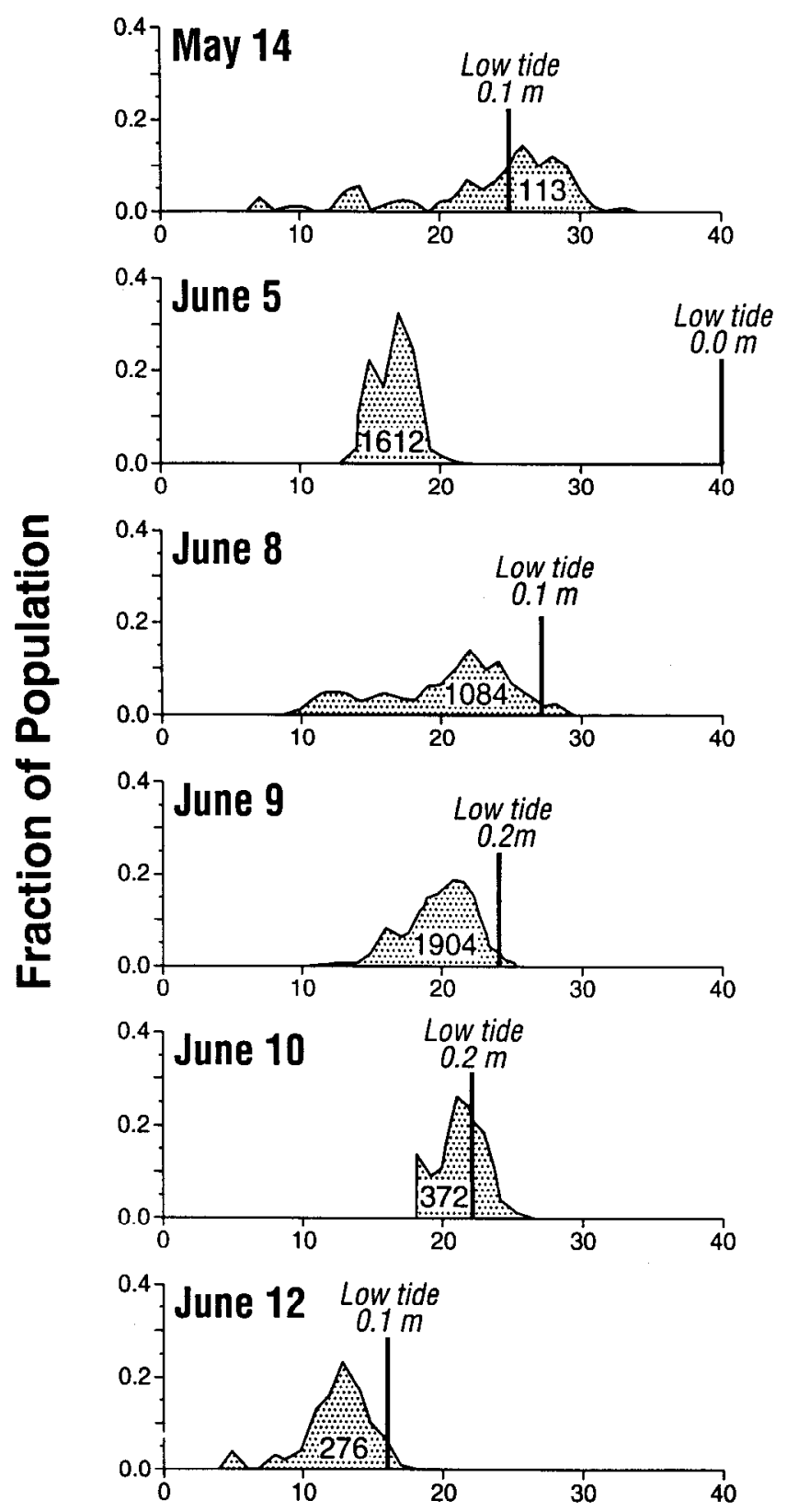

\section{Shore $\leftarrow$ Position $(\mathrm{m}) \rightarrow$ Sea}

Figure 3. The fraction of the population found at each position along transects perpendicular to the shoreline, on a beach at low tide on several days. The vertical black bar marks the average position of the sea's edge at low tide. (The meter markers were not in the same location each day; the profile of the beach changes daily.) The vertical height of each low tide is given beside the vertical line. The total number of clams counted is given in the shaded area. Most days, the population is found shoreward of the sea's edge at low tide, out of reach of any swash. Usually, the clams do not migrate at all within $1 \mathrm{~h}$ of low tide.

Clams chose waves that moved relatively large distances in the shoreward direction. They jumped for such large swash before the swash reached them. How do they predict the size of incoming swash? One testable hypothesis is that there are patterns to the waves. For instance, if the size of incoming swash is correlated with the excursion of the previous backwash, then the excursion of the preceding backwash, $E_{p}$, could be a cue. I found that $\mathbf{E}_{p}$ is not correlated with the next excursion of the swash, $\mathbf{E}$, ( $R^{2}=0.07,0.04,0.28,0.4$, on the 4 days), so it would be a poor predictor of $E$. Indeed the clams are not using $E_{p}$ since $C / T$ does not increase with increasing $\mathbf{E}_{\mathbf{p}}$ (Fig. 4B).

Two variables determine the excursion of the swash, $\mathbf{E}$, the variables $\mathbf{B}_{\mathbf{m}}$ and $\mathbf{S}_{\mathbf{m}}$ (Fig. 1). On some days clams rode swash that moved significantly farther shoreward $\left(\mathbf{B}_{\mathrm{m}}\right)$ than swash they did not ride $(P<0.0001, F$-test, multiple regression with dummy variables, Weisberg,
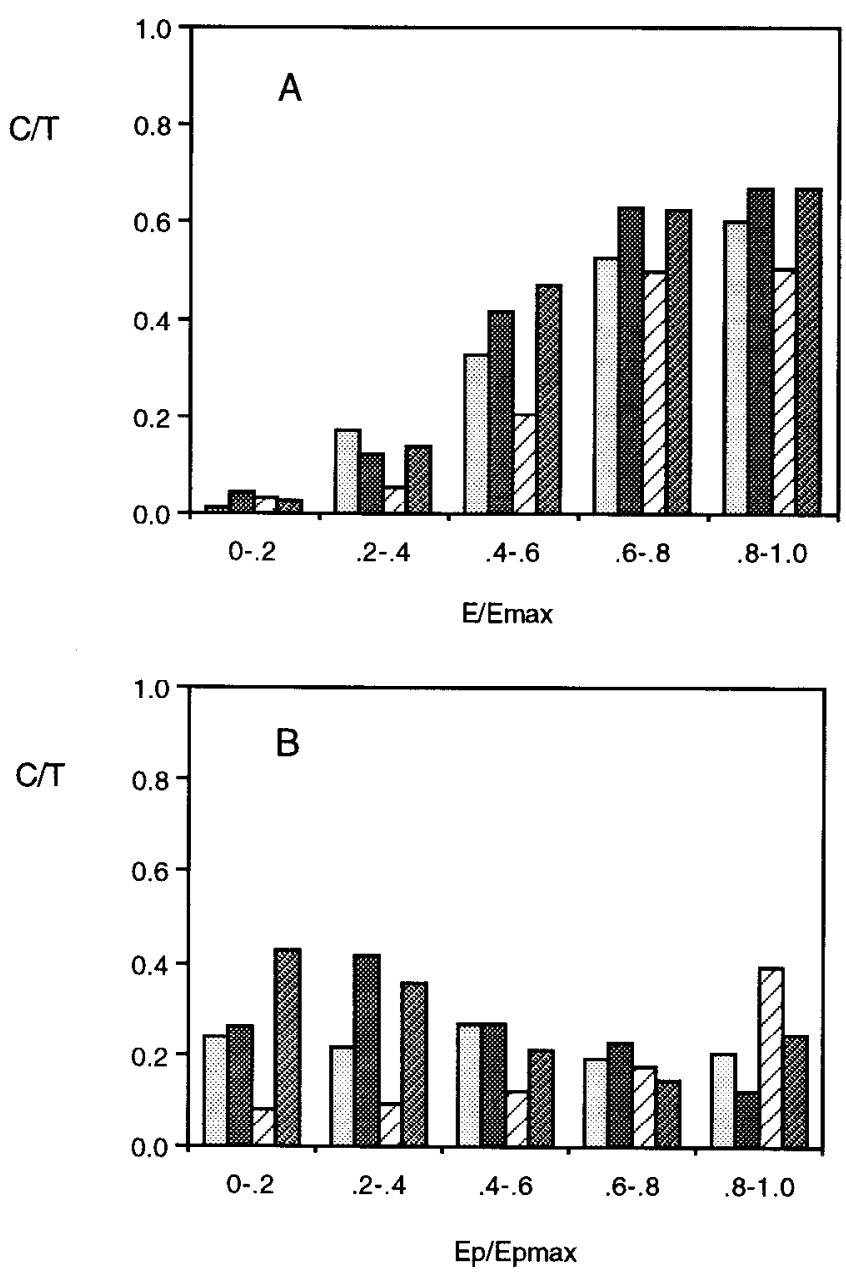

Figure 4. The proportion of swashes in size classes chosen for riding by clams. $C / T$ is chosen waves divided by total waves in a wave size category. Different shading denotes 4 separate days of observations. (A) Half of the largest swashes (high $E / E_{\max }$ ) are ridden, whereas small swashes are almost never chosen. $E / E_{\max }$ is excursion divided by maximum excursion observed on a given day. (B) The proportion of chosen swashes having relatively large excursions of the previous backwashes (large $E_{p}$ / $E_{p \max }$ ). Swashes with large $E_{p}$ are not chosen systematically. D. variahilis choose to ride swashes that have a large excursion, E, not swashes that have a large excursion of the previous backwash, $\mathbf{E}_{\mathbf{p}}$. 
1980). On other days, clams rode waves that started significantly farther seaward $\left(\mathbf{S}_{\mathrm{m}}\right)$ than swash they did not ride $(P<0.0001$, same kind of test). Although on some days clams appear to be riding swash according to extreme values of $\mathbf{B}_{m}$ or $\mathbf{S}_{m}$ relative to the average $\mathbf{B}_{m}$ or $\mathbf{S}_{\mathbf{m}}$ at that time, this pattern is inconsistent among days. In contrast, riding swash with large excursion $\left(\mathbf{B}_{\mathbf{m}}-\mathbf{S}_{\mathbf{m}}\right.$ is applicable to all days.

\section{Discussion}

Comparison of the movements of dead and live clams planted in the sand shows that, during a falling tide, Donax variabilis clams actively emerge into the backwash, which then moves them seaward. Such active emergence contradicts the alternative hypothesis of a more passive role for Donax spp. during migration (see Introduction). For instance, it was suggested that $D$. denticulatus emerges from the sand passively to move seaward during the falling tide (Wade, 1967a). Wade suggested that a $D$. denticulatus clam would detect the increased drying of the sand as the tide receded and respond by retracting its foot and siphons, thus decreasing its purchase in the sand and enabling backwash to scour it from the sand and wash it seaward. In contrast, the current experiment shows that, for $D$. variabilis in the studied beach, mere retraction of the foot would not usually be sufficient to cause dislodgment by erosion (dead clams were dislodged only 50\% of the time). In fact, live clams moved seaward much more often than dead clams, which suggests that live clams actively emerged from, or jumped out of, the sand. Indeed, I have observed jumping responses during times corresponding to falling tides in laboratory experiments on endogenous rhythms (Ellcrs, 1995a). Thus, I conclude that live clams of this species often actively push themselves out of the sand and into the backwash to be moved seaward by flow.

A series of such rides in the backwash becomes a seaward migration. If live clams relied on erosion to initiate their seaward rides in the backwash, only $20 \%$ to $50 \%$ of the population at a given location on the beach could move seaward (as did the dead clams, Fig. 2). Considering that a minimum of three swash-rides is required to complete a migration (minimum beach width divided by maximum excursion), the fraction of the population completing a seaward migration passively would be 0.008 to 0.125 . Therefore, passive erosion could not be used to migrate seaward on these beaches. As a result of active seaward migration, almost the entire population has moved to the lower end of the intertidal at low tide (Figs. 2 and 3 ).

Erosion undoubtedly sometimes forces clams out of the sand. Erosive forces on a clam under the sand are occasionally larger than the force that a clam can excrt with its foot (Ellers, 1988). Although erosion necessitates the ability to cope with (ride in) flow and to dig in again, it does not necessitate migration. D. variabilis use a systematic series of rides in the swash and the backwash to migrate.

This systematic series of seaward swash-rides in $D$. variabilis ends about 0.5 to $1 \mathrm{~h}$ before low tide. At that time the clams cease migrating and are left at or just shoreward of the edge of the sea at low tide (Fig. 3). Migration resumes about 0.5 to $1 \mathrm{~h}$ after low tide, with clams then moving in the shoreward direction. Others have also reported populations of Donax spp. that do not neccssarily follow the water's edge to the low-water limit (see Introduction). In some populations, the location of the population on the beach at low tide follows a regular pattern. For instance, $D$. serra migrates following the position of the low-tide water table (Donn et al., 1986). The water table is further seaward on the beach during spring tides than during neap tides. In laboratory experiments with D. variabilis, an endogenous rhythm has been observed in which a quiescent period occurs around the time of low tide (Ellers, 1995a). During that period, clams do not show jumping responses. The rhythm is thus a proximal cause of the systematic cessation of migration close to low tide in D. variabilis.

When migration resumes in the shoreward direction, many clams in the population can be seen simultaneously jumping out of the sand just shoreward of incoming waves. This behavior has been reported for $D$. semigranosus (Mori, 1938, 1950) and for $D$. variabilis (Turner and Belding, 1957). Not only do the clams jump in front of incoming waves, they jump only for the biggest waves. Several measures of wave size might be appropriate: wave height, breaker height, bore height, distance traveled, and maximum shoreward position that a swash wets.

My quantitative data show that, during the rising tide, these clams ride waves shoreward, using primarily the $20 \%$ of waves that move the largest distance in the shoreward direction. Those are not necessarily the swash that end their travels furthest shoreward; neither are they necessarily the swash that start the furthest seaward. The consequence of riding these largest swash is thus to be at neither the shorewardmost nor the seawardmost extent of the swash-zone. Rather, riding the biggest swash maximizes shoreward distance traveled and minimizes number of swash-rides per migration. In terms of absolute distance, the effect is remarkable-the clams can choose a swash that moves $18 \mathrm{~m}$ shoreward rather than the $1-\mathrm{m}$ excursion of the smallest waves. By timing their active emergence from the sand, D. variabilis clams control their swash-riding.

The clams choose swash with large excursion, E. But they jump before a shoreward swash reaches them. What cucs the clams to jump for these swash? Swashes with large $\mathbf{E}$ are created on dissipative beaches by collapsing 
bores of large height. The initial velocity, $\mathbf{U}_{\mathbf{0}}$, of the swash immediately following bore collapse is given by

$$
\mathbf{u}_{\mathbf{0}}=\mathbf{U}^{\prime}+\mathbf{2} \sqrt{\mathbf{g} \mathbf{h}^{\prime}}
$$

where $\mathbf{U}^{\prime}$ is the speed of the bore front, $\mathbf{h}^{\prime}$ is bore height, and $\mathbf{g}$ is gravitational acceleration. The excursion of the swash is

$$
\mathbf{E}=\frac{\mathbf{U}_{0}}{\mathbf{g} \tan \beta}
$$

where $\beta$ is the slope of the beach. Both the velocity and swash excursion on real beaches were within $10 \%$ of these theoretical predictions (Bradshaw, 1982). Thus if clams could detect the height of the bore, they could predict the swash excursion. Larger bores presumably make louder sounds as they collapse. If the clams listened to the sound of the bore, they could predict the excursion of the swash formed from it.

Anecdotal reports for D. semigranosus (Mori, 1938 , 1950 ) and $D$. variabilis (Turner and Belding, 1957) suggest that during rising tides, sounds created by incoming waves cue the clams to emerge in front of swash. The present study demonstrates that clams emerge in front of swash with large excursion, and eqns (1) and (2) give a mechanism for linking sound production by an incoming wave to the production of a large swash excursion. I have demonstrated appropriate responses by $D$. variabilis to wavelike sounds in the laboratory in the absence of waves or other possible cues (Ellers, 1995a).

Behavior thus controls swash-riding and migration by D. variabilis on these beaches by controlling the timing of emergence of the clams from the sand. Morphology further controls a clam's motion while it is pushed by flow from waves (Ellers, 1995b).

Rather than being at the mercy of the tumultuous milieu of breaking waves, eroding sand, and rip currents at the edge of a beach, these clams make use of flows. Other animals such as mole crabs, some gastropods, and amphipods presumably use similar strategies on exposed beaches. Unlike the familiar paradigm for sessile organisms on rocky shores, in which organisms avoid dislodgment primarily by avoiding flow forces such as streamlining, etc. (Vogel, 1981; Denny, 1988), the parallel paradigm for organisms that live on shifting substrata is that they use flow forces for locomotion.

\section{Acknowledgments}

This research is part of the author's Ph.D. dissertation completed at Duke University. NSERC postgraduate scholarships, Duke University teaching assistantships, and a Cocos Foundation Training Grant in Morphology supported the author. The Lerner-Gray Fund for Marine Research (American Museum of Natural History) and a
Grant-in-Aid of Research from Sigma Xi supported this project. I acknowledge the Duke University Marine Laboratory for use of its facilities. I am grateful to the many friends who selflessly volunteered to assist with field work on the beach. I also thank my thesis supervisor, S. Vogel, and committee members, V. L. Roth, E. J. Shaughnessy, V. A. Tucker, and S. A. Wainwright.

\section{Literature Cited}

Beukema, J. J., and J. de Vlas. 1989. Tidal-current transport of threaddrifting postlarval juveniles of the bivalve Macoma balthica from the Wadden Sea to the North Sea. Mar. Ecol. Prog. Ser. 52: 193200.

Bradshaw, M. 1982. Bores and swash on natural beaches. (oustal Studies Unit Technical Repont No. 82/4. Coastal Studies Unit. Department of Geography, The University of Sydney. Sydney. NSW. Australia.

Denny, M. W. 1988. Biology and the Mechanics of the Wave-Swept Environment. Princeton University Press, Princeton, NJ.

Donn, T. E., Jr., D. J. Clarke, A. McLachlan, and P. du Toit. 1986. Distribution and abundance of Donax serra Röding (Bivalvia: Donacidae) as related to beach morphology. I. Semilunar migrations. J. Exp. Mar. Biol. Ecol. 102: 121-131.

Edgren, R. A. 1959. Coquinas (Donax variabilis) on a Florida beach. Ecology 40: 498-502.

Ellers, O. 1987. Passive orientation of benthic animals in flow. Pp. 45-68 in Signposts in the Sea. Proceedings of a Multidisciplinary Workshop on Marine Animal Orientation and Migration. W. F. Herrnkind and A. B. Thistle, eds. Dept. of Biological Science. Florida State University, Tallahassee.

Ellers, O. 1988. Locomotion via swash-riding in the clam Donax variabilis. Ph.D. Dissertation, Duke University, Durham, NC.

Ellers, O. 1995a. Discrimination among wave-generated sounds by a swash-riding clam. Biol. Bull. 189: 128-137.

Ellers, O. 1995b. Form and motion of Donax variabilis in flow. Biol. Bull. 189: $138-147$

Irwin, T. H. 1973. The intertidal behavior of the bean clam, Donat gouldii Dall, 1921. Veliger 15: 206-212.

Jacobson, M. K. 1955. Observations on Donax fossor Say at Rockaway Beach, New York. Nautilus 68: 73-77.

Katz, C. H., .I. S. Cobb, and M. Spaulding. 1994. Larval behavior, hydrodynamic transport, and potential offshore-to-inshore recruitment in the American lobster Homarus americamus. Mar. Ecol. Prog Ser. 103: 265-273

Martel, A., and F. Chia. 1991. Drifting and dispersal of small bivalves and gastropods with direct development. I. Exp. Mar. Biol. Firol. 150: $131-147$.

McLachlan, A., and P. Hesp. 1984. Faunal response to morphology and water circulation of a sandy beach with cusps. Mar. Ecol Prog. Ser. 19: 133-144.

McLachlan, A., T. Wooldridge, and G. van der Horst. 1979. Tida movements of the macrofauna on an exposed sandy beach in South Africa. J. Zool., Lond. 187: 433-442.

Mikkelsen, P. S. 1981. A comparison of two Florida populations of the coquina clam, Donax variabilis Say, 1822 (Bivalvia: Donacidae). I. Intertidal density, distribution and migration. Veliger 3: 230-239.

Mori, S. 1938. Characteristic tidal rhythmic migration of a mussel. Donax semigranosus Dunker, and the experimental analysis of its behaviour at the flood tide. Dobutsugaku Zasski. $[=Z$ Zool. Mag. (Japan)] 50: $1-12$.

Mori, S. 1950. Characteristic tidal rhythmic migration of a mussel. Donax semigranosus Dunker, and the experimental analysis of its 
behaviour (II). Dobutsugaku Zasski [=Zool. Mag. (Japan)] 59: 8789.

Odendaal, F. J., P. Turchin, G. Hoy, P. Wickens, J. Wells, and G. Schroeder. 1992. Bullia digitalis (Gastropoda) actively pursues moving prey by swash-riding. J. Zool. 228: 103-113.

Shanks, A. L. 1986. Vertical migration and cross-shelf dispersal of larval Cancer spp. and Randalia ornata (Crustacea: Brachyura) off the coast of southern California. Mar. Biol. 92: 189-199.

Smith, N. P., and A. W. Stoner. 1993. Computer simulation of larval transport through tidal channels: Role of vertical migration. Estucarine Coastal Shelf Sci. 37: 43-58.

Sörlin, T. 1988. Floating behaviour in the tellinid bivalve Macoma balthica (L.) Oecologia 77: 273-277.
Turner, H. J., Jr., and D. L. Belding. 1957. The tidal migrations of Donax variabilis Say. Limnol. Oceanogr. 2: 120-124.

Vogel, S. 1981. Life in Moving Fluids. Princeton University Press, Princeton, NJ.

Wade, B. 1967a. Studies on the biology of the West Indian Beach clam, Donax denticulatus Linné. 1. Ecology. Bull. Mar. Sci. 17: 149174.

Wade, B. 1967b. On the taxonomy, morphology, and ecology of the beach clam, Donax striatus Linné. Bull. Mar. Sci. 17: 723-740.

Weisberg, S. 1980. Applied Linear Regression. John Wiley and Sons, New York.

Worcester, S. E. 1994. Adult rafting versus larval swimming: dispersal and recruitment of a botryllid ascidian on eelgrass. Mar. Biol. 121: 309-317. 